\title{
DESENVOLVIMENTO RURAL NO RIO GRANDE DO SUL (2010/2013): UMA ANÁLISE MULTIDIMENSIONAL
}

\author{
Sibele Vasconcelos de Oliveira ${ }^{1}$ \\ Cristiéle de Almeida Vieira ${ }^{2}$ \\ Rita Inês Paetzhold Pauli ${ }^{3}$
}

\section{RESUMO}

A determinação de variáveis que compõe o conjunto de fatores que envolvem o desenvolvimento rural é complexa, de forma que sua análise demanda abordagens multidimensionais. Destarte, o presente estudo propõe a construção de um índice de desenvolvimento rural para o Rio Grande do Sul, considerando a disponibilidade de dados estatísticos para o interstício temporal de 2010/2013. A metodologia empregada avalia cinco dimensões do desenvolvimento: População, Renda, Educação, Bemestar Social Rural e Meio Ambiente. Além disso, são apresentados resultados comparados para o estado gaúcho e o comportamento médio das variáveis em nível nacional. Dentre os principais resultados, pode-se estimar o índice de desenvolvimento rural para o RS em 0,69. Em termos gerais, observou-se uma situação relativamente mais positiva do Rio Grande Sul em relação à situação média do Brasil. A dimensão de análise que apresentou pior resultado quando da construção do índice de desenvolvimento rural foi a renda, seguida da dimensão população. Ressalva-se a limitação dos dados sobre a dimensão ambiental, que permite apenas inferir sobre o marco institucional. Por fim, julga-se importante a implementação de políticas públicas que visem minimizar as vulnerabilidades da população rural e da sustentabilidade ambiental, em um movimento de busca pela ampliação da qualidade de vida e bem-estar atual e das gerações futuras.

Palavras Chave: desenvolvimento rural, educação, meio ambiente, população, renda.

\section{RURAL DEVELOPMENT IN RIO GRANDE DO SUL (2010/2013): A MULTIDIMENSIONAL ANALISYS}

\section{ABSTRACT}

The determination of variables that compose the set of factors that involve rural development is complex, so that its analysis demands multidimensional approaches.

\footnotetext{
${ }^{1}$ Graduada em Ciências Econômicas (UFSM). Especialista em Finanças (UNIFRA). Mestra em Extensão Rural (UFSM). Doutora em Agronegócios (UFRGS). Docente no Programa de Pós-Graduação em Economia e Desenvolvimento e no Programa de Pós-Graduação em Agronegócios da Universidade Federal de Santa Maria (UFSM). E-mail: sibele.oliveira@ufsm.br

2 Graduada em Ciências Econômicas (UFSM). Mestranda em Economia (UEM). E-mail: crissavieira@gmail.com

${ }^{3}$ Graduada em Ciências Econômicas (UFSM). Mestra em Economia Rural (UFPB). Doutora em Ciência Econômica (UNICAMP). Docente no Programa de Pós-Graduação em Economia e Desenvolvimento da Universidade Federal de Santa Maria (UFSM). E-mail: rita.pauli@gmail.com
} 
In view of this, the present study proposes the construction of a rural development index for Rio Grande do Sul, considering the availability of statistical data for the period 2010/2013. The methodology used evaluates five dimensions of development: Population, Income, Education, Rural Social Welfare and Environment. In addition, comparative results are presented for the state of Rio Grande do Sul and the mean behavior of variables at the national level. Among the main results, the rural development index for RS can be estimated at 0.69. In general, terms, the relatively positive situation of Rio Grande Sul in relation to the average situation in Brazil was observed. The analysis dimension that presented the worst result when constructing the rural development index was income, followed by the population dimension. It is important to limit the data on the environmental dimension, which only allows inferring about the institutional framework. Finally, it is considered important to implement public policies aimed at minimizing the vulnerability of the rural population and environmental sustainability, in a search for the expansion of the quality of life and well-being present and future generations.

KEY WORDS: education, environment, income, population, rural development.

\section{INTRODUÇÃO}

O estado do Rio Grande do Sul, localizado na região do Sul do Brasil, está entre as cinco unidades federativas mais populosas do país, com 10.695.532 habitantes. Conforme dados do Instituto Brasileiro de Geografia e Estatística (IBGE, 2017), aproximadamente $14,9 \%$ da população gaúcha reside no meio rural, desenvolvendo atividades produtivas e sociais de diversas naturezas. Em termos de organização produtiva, o estado gaúcho possui cerca de 440 mil estabelecimentos agropecuários, distribuídos em 20,3 milhões de hectares. As estimativas mostram que 1,2 milhões de pessoas estão ocupadas em atividades agropecuárias e que a agropecuária representa 11,6\% do Valor Adicionado Bruto (IBGE, 2014; FEIX; LEUSIN JÚNIOR; AGRANONIK, 2017).

A despeito da importância da agropecuária para a geração de emprego e renda no Rio Grande do Sul, discute-se também acerca da qualidade de vida da população rural. Esta vincula-se às tecnologias utilizadas nos processos produtivos implementados no campo, bem como às condições de acesso a bens e serviços propulsores do bem-estar social. Assim sendo, debate-se sobre o próprio fenômeno do desenvolvimento rural, multifacetado e complexo.

A perspectiva abordada neste estudo concorda com as definições de desenvolvimento multidimensional de Sen (2010), Schneider (2003) e Kageyama (2002; 2004), que enfatizam a importância da pesquisa aos indicadores socioeconômicos quando da análise das transformações nos espaços rurais. Em suma, o desenvolvimento rural não pode ser definido só pelo processo de crescimento econômico, nem medido somente pela renda per capita, mas como um processo que integra as dimensões econômicas, socioculturais, político-institucionais e ambientais (PLOEG et al., 2000; KAGEYAMA, 2004 e 2008; CONTERATO, 2008; STEGE; PARRÉ, 2013).

Destarte, o presente estudo tem por objetivo construir um Índice de Desenvolvimento Rural para o estado do Rio Grande do Sul compreendendo o período de análise de 2010/2013. Além disto, realiza-se uma análise comparativa dos resultados gaúchos em relação aos resultados nacionais. Prezando pela análise multidimensional, este índice foi construído levando-se em consideração indicadores de diferentes naturezas: População, Educação, Renda, Bem-estar e Meio Ambiente. Diante do exposto, a problemática deste trabalho é: Quais são os indicadores do Rio 
Grande do Sul que apresentam maior vulnerabilidade no Índice de Desenvolvimento Rural?

Além desta introdução, o artigo subdivide-se em mais quatro seções. $\mathrm{Na}$ seção seguinte, encontra-se breve revisão teórica sobre a evolução do conceito de desenvolvimento e de sua particularidade rural. A terceira seção compreende a metodologia e os procedimentos adotados para estimação do Índice de Desenvolvimento Rural para o Rio Grande do Sul. Na sequência, na quarta e quinta seções são apresentadas a análise de resultados e as considerações finais.

\section{INTERPRETAÇÕES ACERCA DO FENÔMENO DO DESENVOLVIMENTO E DO DESENVOLVIMENTO RURAL}

A diferenciação dos conceitos de desenvolvimento e crescimento intensificou-se com a Segunda Guerra Mundial, pois com a guerra muitos países ficaram com sua estrutura social, econômica e política desestabilizada. Esse processo implicou na depreciação infraestrutural, na geração de elevados índices de desemprego e pobreza extrema em muitas regiões do globo terrestre.

Para reduzir este estado de miséria, várias políticas de desenvolvimento foram adotadas. Segundo Sunkell e Paz (1988), este tema foi tratado em todos os países, principalmente os que participaram diretamente da guerra. A Organização das Nações Unidas (ONU) criada em 1945 no pós-guerra, era composta por 51 países e tinha como função promover o crescimento juntamente com o aumento da qualidade de vida das pessoas, isto é, o desenvolvimento (OLIVEIRA, 2002).

Desta forma, destacam-se duas correntes de pensamento prevalecentes sobre o conceito de desenvolvimento: a) neoclássica de Harrod e Domar, que consideram crescimento sinônimo de desenvolvimento; e b) cepalina e marxista, que apesar de apresentarem algumas diferenças, conceituam o crescimento como decorrente de fenômenos puramente monetários, enquanto o desenvolvimento, grosso modo, centrar-se-ia em mudanças na qualidade de vida da sociedade (SOUZA, 2012).

Vale ressaltar que o presente estudo, em suas linhas gerais, identifica-se com a segunda corrente supracitada. Entretanto, para permitir o diagnóstico mais específico, incursiona-se de forma mais detida em interpretações de trabalhos mais recentes que buscaram captar as vulnerabilidades nas diferentes dimensões do desenvolvimento.

Neste sentido, desde o primeiro Relatório sobre Desenvolvimento Humano elaborado pelo Programa das Nações Unidas para o Desenvolvimento (PNUD, 1990), há consenso que o crescimento do Produto Interno per capita dos países é insuficiente como medida de desenvolvimento (KAGEYAMA, 2004). Com o objetivo de formular um índice que captasse a complexidade que envolve as variáveis do desenvolvimento dos países, Amartya Sen ${ }^{4}$ e Mahbud ul Hag criaram o Índice de Desenvolvimento Humano (IDH) em 1993, que se tornou referência na literatura especializada.

O desenvolvimento avaliado por esta perspectiva engloba análise de aspectos econômicos e sociais. Em especial, contempla o estudo de variáveis de

\footnotetext{
${ }^{4}$ Outra contribuição de Amartya Sen é sua concepção teórica "abordagem das capacitações" em que considerou o desenvolvimento como expansão das liberdades econômicas, sociais e políticas. Ou seja, Sen (2010) crítica a concepção ortodoxa de analisar o desenvolvimento (pela renda) e destaca a necessidade de desviar a atenção dos meios para os fins. Por exemplo, o Produto Interno Bruto de um país é um meio de expandir as liberdades enquanto os fins seriam a remoção das principais fontes de privação como: pobreza e tirania, carência de oportunidade econômica, negligência dos serviços públicos, desigualdade entre outros fatores que inferem diretamente no bem-estar da vida em sociedade. Segundo Sen (2010), o desenvolvimento ocorre quando há a eliminação de privações de liberdades que limita as escolhas e as oportunidades das pessoas.
} 
diversas origens, a incluir a renda e indicadores referentes à qualidade de vida das pessoas, como o acesso à educação e saúde, desigualdade e demais fatores que interferem no bem-estar da população.

Chalita (2005) define desenvolvimento rural como uma noção que traduz as alterações políticas, sociais e econômicas em uma conotação mais ampla:

\begin{abstract}
O que muda então nas concepções de desenvolvimento rural é o peso atribuído aos seguintes elementos: conhecimento técnicocientíficos produzidos de forma convencional em instituições de pesquisa ou no campo da experiência; articulação adequada para o aproveitamento de sinergias que otimizem potencialidades para atender o exercício da democracia; outras formas de saberes locais incluindo formas de gestão dos recursos e sua articulação com interesses sociais; sustentabilidade e desenvolvimento visando não apenas o ponto de vista técnico-econômico (a maximização na reprodução dos recursos naturais), como também do ponto de vista da igualdade e justiça social, o que implica compromisso intrasocietário e intergeracional e participação dos atores sociais envolvidos em um processo além dos usualmente adotados para prospecção de demandas (CHALITA, 2005, p.108).
\end{abstract}

Graziano da Silva (2001) evidencia que não há estratégia de desenvolvimento possível que não preconize a redução de pobreza. Na mesma linha de análise, Schneider (2010) destaca que as diferentes abordagens sobre o desenvolvimento rural no Brasil enfocam, direta ou indiretamente, as ações de combate à pobreza e às múltiplas fontes de vulnerabilidade social que afligem as populações rurais. Além disto, afirma que os estudos e pesquisas devem estar atentos às relações que afetam as condições de vida da população rural. Sobretudo, o desenvolvimento deve ser compreendido sob a perspectiva da mudança social.

Tendo em vista a magnitude da população rural no mundo e no Brasil, Abramovay (2000, p. 26) explicita que a noção de desenvolvimento deve encontrar uma aplicação específica, principalmente pelo que o meio rural tem a oferecer para a sociedade e também pelas dificuldades das regiões urbanizadas em gerar oportunidades de trabalho e integração. Conforme destaca o autor, "a noção de desenvolvimento rural é certamente normativa, mas sua utopia apoia-se em um potencial que a sociedade pouco conhece e, consequentemente, pouco valoriza" (ABRAMOVAY, 2000, p 26).

Considerando as especificidades do espaço rural e seus condicionantes socioeconômicos, edafoclimáticos e tecnológicos, entende-se por desenvolvimento rural um processo evolutivo, interativo e hierárquico (SCHNEIDER, 2004, p. 99). Sobretudo, Waquil, Gianluppi e Mattos (2005, p. 139) argumentam que a literatura contemporânea sobre desenvolvimento aponta para a multidimensionalidade destes processos. Para os autores, "quando o desenvolvimento no espaço rural é debatido, muitas vezes girando em torno do conceito de desenvolvimento sustentável, a dimensão econômica deve ser complementada por outras dimensões, como a sóciodemográfica e a ambiental” (WAQUIL; GIANLUPPI; MATTOS, 2005, p. 139).

Sob essa perspectiva que o presente estudo busca contribuir, com o entendimento acerca do desenvolvimento rural no Rio Grande do Sul. Especificamente, propõe-se a estimação de um Índice de Desenvolvimento Rural composto por múltiplas dimensões e indicadores. A seguir, discorre-se sobre as particularidades dos procedimentos metodológicos implementados. 


\section{METODOLOGIA}

A construção de análises multidimensionais, de acordo com Seth e Villar (2017), é comumente realizada sob duas primordiais estratégias: i) observando o progresso das dimensões separadamente; e/ou ii) agregando em um índice o desempenho de todas as variáveis observadas. Destarte, ao passo que se construiu um índice de desenvolvimento rural, também se optou por empregar ferramentas de estatística descritiva para avaliar o comportamento das variáveis elencadas para análise durante o período de 2010 a 2013.

Os procedimentos metodológicos implementados para cálculo do Índice de Desenvolvimento Rural (IDR) seguiram orientações gerais presentes na abordagem desenvolvida por Kageyama (2004). Privilegiou-se a análise das seguintes dimensões: População, Bem-Estar Social, Renda, Meio Ambiente e Educação. Para tanto, foram selecionados indicadores para cada uma das dimensões referenciadas, conforme descrito no quadro 01.

Quadro 1 - Dimensões e indicadores componentes do IDR.

\begin{tabular}{|c|c|c|}
\hline Dimensão & Indicador & Ano \\
\hline \multirow{3}{*}{ População } & Evolução da população rural no Brasil e no Rio & \multirow{3}{*}{2010} \\
\hline & Grande do Sul & \\
\hline & Densidade demográfica brasileira e rio-grandense & \\
\hline Educação & $\begin{array}{l}\text { Taxa de analfabetismo da população rural de } 15 \\
\text { anos ou mais }\end{array}$ & 2010 \\
\hline Bem-Estar Social & $\begin{array}{l}\text { Presença de serviços básicos (água canalizada, ilu- } \\
\text { minação elétrica e telefone celular) no meio rural }\end{array}$ & 2010 \\
\hline Renda & Rendimento em salário mínimo da população rural & 2010 \\
\hline \multirow{7}{*}{ Meio Ambiente } & Estrutura na área de Meio Ambiente & \multirow{7}{*}{2013} \\
\hline & Conselho Municipal de Meio Ambiente & \\
\hline & Legislação Específica para tratar de Meio Ambiente & \\
\hline & Fundo de Meio Ambiente & \\
\hline & Comitê de Bacia Hidrográfica & \\
\hline & Iniciativa na área de Consumo Sustentável & \\
\hline & Comissão Interinstitucional de Educação Ambiental & \\
\hline
\end{tabular}

Fonte: Adaptado de IBGE (2017).

Para a estimação do IDR foi atribuído o mesmo peso (valor 1) a cada dimensão analítica, assim como para seus respectivos indicadores. No caso das dimensões que tinham mais de um indicador, foi realizada a média aritmética simples. Ainda, para os casos em que a unidade de medida não é uma proporção, segundo Kageyama (2004), considerou-se como peso 1 o melhor resultado entre os anos estudados e calculou-se o menor resultado como proporção deste. Sendo assim, temse que o IDR é expresso como: 


$$
I D R=X 1+X 2+X 3+X 4+X 5
$$

onde as dimensões são: X1 (População), X2 (Educação), X3 (Bem-Estar Social), X4 (Renda) e X5 (Meio Ambiente). Salienta-se que o índice varia de 0 a 1, sendo 0 (zero) a representação da pior situação em termos de desenvolvimento rural multifacetado e 1 (um) a representação da situação excelente.

Por sua vez, o recorte temporal de análise (2010/2013) foi realizado com base na disponibilidade de informações estatísticas dispostas pelo Instituto Brasileiro de Geografia e Estatística (IBGE) e pelo portal DATASUS. Ressalva-se que, apesar das conclusões encontradas fornecerem elementos importantes para a compreensão do desenvolvimento rural no Rio Grande do Sul para o interstício citado, devido à insuficiência de dados estatísticos, não se pode promover uma comparação mais completa de todos os resultados identificados com aqueles encontrados por Kageyama $(2004)^{5}$. Logo, a título de complementação analítica, realiza-se análise do IDR para o estado do Rio Grande do Sul à luz do contexto rural do Brasil.

Ademais, em complementação ao cálculo do IDR, optou-se por descrever o comportamento dos indicadores que compõem cada dimensão ao longo do tempo. A análise descritiva temporal foi desenvolvida para aquelas variáveis cujas informações estatísticas estavam disponíveis às pesquisadoras.

\section{ANÁLISE DE RESULTADOS}

Nesta seção são apresentados os resultados da pesquisa após avaliação dos dados secundários e implementação de ferramentas em estatística descritiva. As cinco dimensões abordadas para mensurar o grau de desenvolvimento rural no Rio Grande do Sul são População, Educação, Bem-Estar Social, Renda e Meio Ambiente. Por fim, a análise do Índice de Desenvolvimento Rural foi construída a partir dos resultados das subseções 4.1 a 4.5 .

\subsection{DIMENSÃO POPULAÇÃO}

As pressões exercidas pela industrialização da economia brasileira conformaram os traços mais gerais do movimento da população rural. Esse processo, conforme explicitado por Rangel (2000), é principal causa da crise agrária, sendo decorrente da expulsão excessiva de pessoas do campo para a cidade. Ao mesmo tempo, a concentração de terras aparece como um dos fatores explicativos da pobreza rural.

Vale ressaltar que outros autores clássicos e de vanguarda da economia brasileira, dentre eles Caio Prado Jr. (1987), reconhecem que os segmentos mais abastados da população brasileira eram orientados potencialmente para o setor agroexportador e que, devido à estrutura fundiária concentradora e monopolística, reproduziu uma população desprovida dos meios de produção com uma baixa qualidade de vida no campo.

Destaca-se que, em 1960, a população rural do Rio Grande do Sul representava em torno de $55 \%$ da população total gaúcha, mesmo percentual que a média brasileira, porém menor de quando analisada toda Região Sul (Paraná, Santa Catarina e Rio Grande do Sul). Com o passar dos anos, este percentual foi reduzido, de $44 \%$ em 1970, para 16\% em 2010. A Região Sul, seguindo a mesma tendência,

\footnotetext{
${ }^{5}$ Os resultados encontrados por Kageyama (2004) acerca do desenvolvimento rural no Rio Grande do Sul referem-se até o ano de 2002.
} 
apresentou queda expressiva da população rural, que em 1970 representava $55 \%$ da população total e, em 2010, $15 \%$.

Em 1970, o Rio Grande do Sul, em 1970 concentrava 46\% da população no meio rural. A porcentagem de pessoas vivendo nos espaços rurais decaiu para $32 \%$ em 1980, 23\% em 1991 e 18\% em 2000. Finalmente, conforme dados estatísticos divulgados pelo IBGE (2010), apenas $15 \%$ da população gaúcha vivia no meio rural em 2010, como pode ser observado na figura 1.

Figura 1 - População rural no Brasil e Rio Grande do Sul (1960 - 2010).

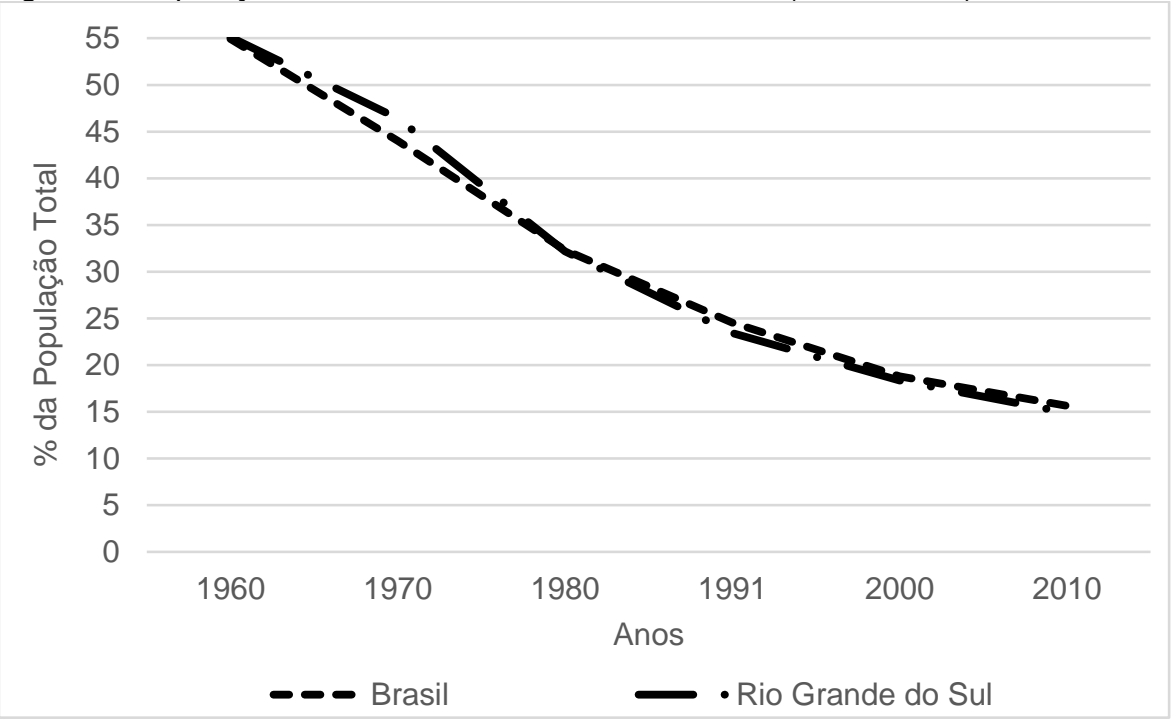

Fonte: Adaptado de IBGE (2010).

A figura 2 apresenta os dados referentes à densidade demográfica para o Brasil e Rio Grande do Sul para o interstício de 1872-2010. Conforme o IBGE (2010), a densidade demográfica é uma medida da distribuição espacial da população e possibilita a análise da concentração (ou dispersão) desta no espaço geográfico.

A densidade demográfica, embora incluindo a área urbana, é um importante indicador do desenvolvimento rural, pois quanto maior a densidade demográfica, maior será a intensidade das redes sociais, econômicas e territoriais (KAGEYAMA, 2006). Desta forma, a densidade demográfica gaúcha e brasileira é utilizada para compor o indicador da Dimensão População deste estudo.

De forma geral, observa-se que a densidade demográfica no Rio Grande do Sul sempre foi superior a nacional. Em 1960, o número médio de habitantes por $\mathrm{km}^{2}$ no Brasil e no Rio Grande do Sul eram relativamente baixos, respectivamente, de 8,34 e 19,34 hab/km². Mais recentemente, em 2010, o Rio Grande do Sul possuía 39,79 $\mathrm{hab} / \mathrm{km}^{2}$ e o Brasil detinha densidade de 22,43 hab/km². 
Figura 2 - Densidade Demográfica do Rio Grande do Sul e Brasil.

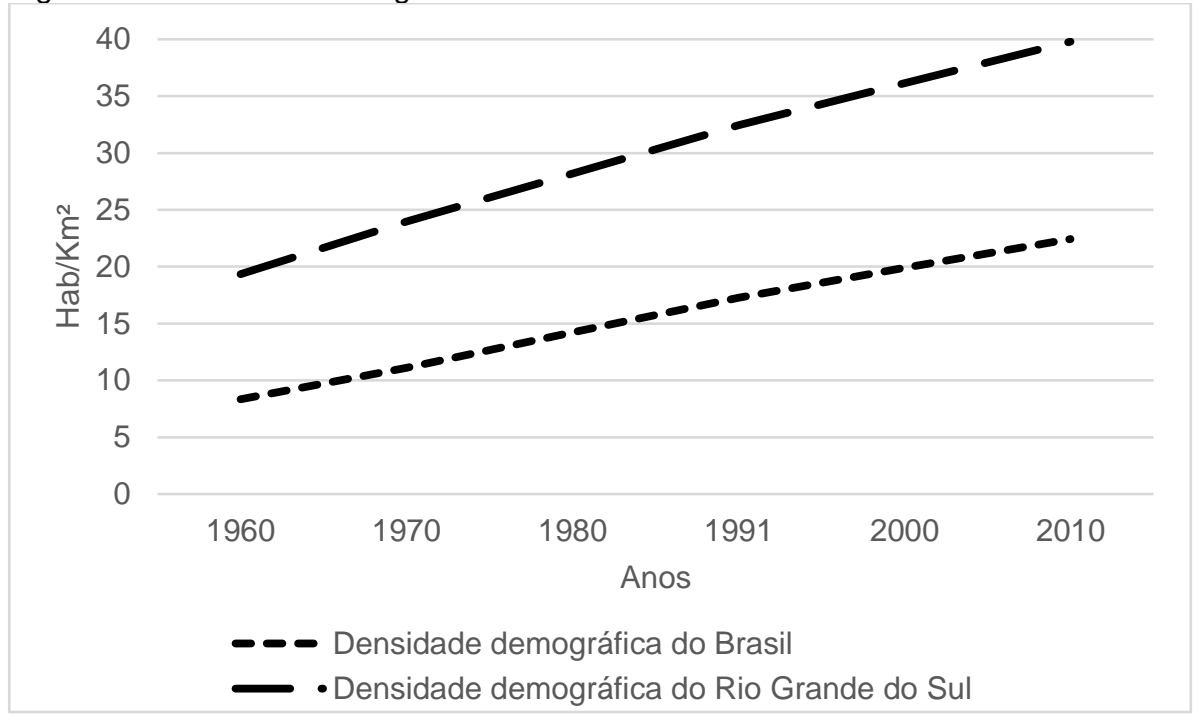

Fonte: Adaptado de IBGE (2010).

O relatório intitulado Tendências Demográficas indica que, no período entre 1940 e 2000, o crescimento desigual das formas de penetração e ocupação econômica condicionou irregularidades no aumento da população em várias regiões do Brasil (IBGE, 2007, p. 18). Neste ínterim, especialmente as regiões Sudeste e Sul apresentaram expressivos deslocamentos de trabalhadores agrícolas, fenômeno acompanhado da modernização da agricultura e da abertura de novas fronteiras agrícolas, além do próprio avanço da industrialização (IBGE, 2007).

Sendo assim, pode-se observar que os gráficos 01 e 02 remetem às seguintes conclusões: a) houve redução importante da população rural, que migrou para o meio urbano, fenômeno decorrente não apenas da industrialização do país, mas também condicionado pelo processo de modernização e industrialização da agricultura, que utilizou processos menos intensivos no fator trabalho no campo; b) a densidade demográfica mais concentrada decorre, fundamentalmente, do próprio movimento migratório que estruturalmente se impôs no desenvolvimento da economia brasileira ${ }^{6}$.

\subsection{DIMENSÃO EDUCAÇÃO}

A educação é um importante indicador de desenvolvimento. Segundo o Ministério da Educação e Cultura (1979), a educação no meio rural deve ser abrangente e global, com a preocupação constante pela promoção coletiva, enraizada no próprio meio e voltada para sua história, seu contexto econômico-geográfico, seus

\footnotetext{
${ }^{6}$ Há vários fatores que poderiam ser mencionados no contexto desta discussão, porém se afastariam do escopo mais específico que norteia esse trabalho. Um exemplo importante de incursões que deveriam ser efetuadas de forma mais detida é o caso da avaliação das implicações do Sistema Nacional de Crédito Rural, implementado na década de 1960 no Brasil e que, dentre outros fatores, originou uma territorialização da burguesia brasileira. Para mais informações, consultar Delgado (1985).
} 
comportamentos e aspirações psicossociais. Conforme Ney e Hoffmann (2009), a qualidade de vida das pessoas está diretamente vinculada a seu nível educacional, ou seja, uma população com mais acesso à educação apresenta maiores oportunidades em elevar o nível de produtividade do trabalho, de renda e participação na vida social e política do país.

O Ministério da Educação e Cultura (1979) expõe alguns elementos que o governo deve desempenhar na oferta de educação rural: i) contribuir para autopromoção do homem do campo a partir de seu contexto cultural; ii) desenvolver a compreensão do meio e a busca de soluções para seus problemas; iii) estimular a organização da população rural em relação àqueles aspectos que são de interesse comum para obter uma melhor distribuição de oportunidades entre todos seus membros; e, por fim, iv) capacitar a população rural para uma melhor utilização dos recursos disponíveis.

A Dimensão Educação, neste trabalho, é representada pelo indicador taxa de analfabetismo da população rural com idade superior a 14 anos. Na tabela 1 , encontram-se os valores censitários de 1991, 2000 e 2010 para o Brasil e para o Rio Grande do Sul.

Tabela 1 - Taxa de analfabetismo da população rural de 15 anos ou mais (\%).

\begin{tabular}{rrr}
\hline Ano & Brasil & Rio Grande do Sul \\
\hline 1991 & 39,36 & 14,53 \\
2000 & 9,64 & 5,3 \\
2010 & 22,89 & 8,24 \\
\hline
\end{tabular}

Fonte: Adaptado de DATASUS (2010).

De 1991 a 2000, a taxa de analfabetismo da população rural de 15 anos ou mais decaiu 24,83 pontos percentuais no caso brasileiro e 9,23 no caso do Rio Grande do Sul. Já na passagem de 2000 para 2010, o analfabetismo aumentou 13,22 pontos percentuais no Brasil e 2,94 no Rio Grande do Sul, apontando que os resultados para o estado gaúcho foram menos perversos. Salienta-se que o Rio Grande do Sul tem a segunda menor taxa de analfabetismo rural dentre todos estados brasileiros, dados aquém somente dos apresentados pelo estado de Santa Catarina.

A melhor posição relativa do Rio Grande do Sul frente a média nacional é explicada parcialmente pela inscrição da educação rural no contexto estruturador da oferta de ensino do estado. O Rio Grande do Sul é a única unidade da federação com tal disposição legal, que supera a abordagem compensatória das políticas para o setor agrícola e aponta para a liberdade política, igualdade social, direito ao trabalho e saúde, e conhecimento dos trabalhadores rurais (MINISTÉRIO DA EDUCAÇÃO, 2012). Ainda segundo o Ministério da Educação (2012), no artigo 216 de sua Carta, afirma-se que para cada grupo de escolas de ensino fundamental incompleto na área rural haverá uma escola central com ensino completo a fim de assegurar um número de vagas suficientes para atender toda demanda rural.

Apesar dessas particularidades, quando os resultados são comparados ao trabalho de Kageyama (2004), constata-se que a Dimensão Educação obteve piora em seus indicadores no interstício avaliado. Enquanto que de 1991 para 2000 as mudanças visualizadas foram positivas, de 2000 para 2010 o aumento do percentual de pessoas analfabetas na área rural pode representar a queda no bem-estar social e na qualidade de vida da população rural.

De fato, conforme atestam Ney e Hoffmann (2009), o acesso ao ensino é determinante sobre o nível de qualidade de vida das pessoas. Sob a perspectiva dos 
autores, o baixo nível de escolaridade da população rural restringe o crescimento das atividades produtivas, especialmente as mais dinâmicas. "Outra preocupação, ainda mais grave, é o fato de o nível de investimento em capital humano ser tão menor quanto mais pobre é a família" (NEY; HOFFMANN, 2009, p. 148). Logo, é a educação é capaz de promover liberdades e quando não desenvolvida pode gerar privações importantes.

\subsection{DIMENSÃO RENDA}

A renda é uma das variáveis observadas na análise do desenvolvimento socioeconômico, sua importância está associada ao seu potencial em proporcionar condições passíveis de alcançar o bem-estar social. Para Bonnal (2013), a privação de renda está entre os principais determinantes para a pobreza rural. Conforme dados do Ministério do Desenvolvimento Social e Combate à Fome (MDS, 2015), a incidência da extrema pobreza no meio rural brasileiro é de $25,5 \%$.

Assim sendo, o presente estudo analisa o rendimento, em salário mínimo ${ }^{7}$ da população rural para o ano de 2010, tanto para o Brasil quanto para o Rio Grande do Sul, conforme tabela 2.

Tabela 2 - Rendimento da população rural (em \% de salário mínimo - 2010).

\begin{tabular}{lrr}
\hline Rendimento & Brasil & Rio Grande do Sul \\
\hline Até 1/4 de salário mínimo & 27,1 & 8,95 \\
Mais de 1/4 a 1/2 salário mínimo & 18,73 & 15,35 \\
Mais de 1/2 a 1 salário mínimo & 15,14 & 30,56 \\
Mais de 1 a 2 salários mínimos & 6,18 & 23,18 \\
Mais de 2 a 3 salários mínimos & 1,25 & 6,08 \\
Mais de 3 a 5 salários mínimos & 0,57 & 2,64 \\
Mais de 5 salários mínimos & 0,3 & 1,41 \\
Sem rendimento & 30,73 & 11,83 \\
\hline
\end{tabular}

Fonte: Adaptado de IBGE (2010).

Entre os grupos salariais descritos pela tabela 2, observa-se que $60,97 \%$ dos brasileiros residentes no rural auferiam rendimento inferior ou equivalente a um salário mínimo ${ }^{8}$. Ainda para o período analisado, $30,73 \%$ não possuíam renda e $27,1 \%$ auferiam apenas $1 / 4$ do salário mínimo. No caso gaúcho, o cenário é relativamente mais favorável, em que $54,86 \%$ da população rural do Rio Grande do Sul percebia menos ou o equivalente a um salário mínimo mensal. Além disso, $11,83 \%$ da população rural gaúcha não possuía renda e $30,56 \%$ das pessoas que vivem no meio rural auferiam renda entre $1 / 2$ e 1 salário mínimo mensal. Vale salientar que apenas $0,87 \%$ da população brasileira rural e $4,05 \%$ da população gaúcha rural recebem mais de três salários mínimos.

\footnotetext{
${ }^{7} \mathrm{O}$ salário mínimo para atender as necessidades básicas do trabalhador e de sua família é estimado levandose em consideração as despesas em moradia, alimentação, educação, saúde, lazer, vestuário, higiene, transporte e Previdência Social (DIEESE, 2017). Vale lembrar que, para o meio rural, uma expressiva parte da renda é composta pelo autoconsumo, indicador não considerado na análise do IBGE quando da elaboração das estatísticas.

${ }^{8}$ Conforme Lei $12.255 / 2010$, no ano de 2010 o salário equivalia a $\mathrm{R} \$ 510,00$.
} 


\subsection{DIMENSÃO BEM-ESTAR SOCIAL}

Sabe-se que o crescimento do bem-estar social não está necessariamente atrelado ao aumento da renda individual ou familiar. De acordo com Sen (2000), o bem-estar social deve ser percebido pelas liberdades desfrutadas pelos indivíduos quando vivem em sociedade. As liberdades individuais e instrumentais podem estar representadas pelas facilidades econômicas, oportunidades sociais, garantias de transparência e segurança protetora que as pessoas têm acesso.

Vale lembrar que alguns componentes importantes do bem-estar social da população rural são de difícil mensuração, especialmente aqueles vinculados a acessibilidade aos mercados de consumo, de inserção mais abrangente no mercado de trabalho e em diferentes programas governamentais ${ }^{9}$ e não-governamentais. A despeito da dificuldade de representação, a dimensão Bem-Estar Social elencada nesta pesquisa é composta por três indicadores básicos e que enfatizam, primordialmente, os aspectos infraestruturais dos estabelecimentos agropecuários: i) presença de água canalizada na residência rural; ii) iluminação pública no meio rural e iii) telefone celular dos habitantes do meio rural.

A Tabela 3 ilustra a relação percentual dos habitantes da área rural com acessibilidade aos respectivos bens e serviços sociais para o Brasil e o Rio Grande do Sul.

Tabela 3 - Indicadores de bem-estar social para Brasil e Rio Grande do Sul (\%).

\begin{tabular}{l|r|r|r|r|r|r}
\hline \multirow{2}{*}{ Anos } & \multicolumn{2}{|c|}{$\begin{array}{c}\text { Acesso à água } \\
\text { canalizada }\end{array}$} & \multicolumn{2}{c|}{$\begin{array}{c}\text { Acesso à iluminação } \\
\text { elétrica }\end{array}$} & \multicolumn{2}{c}{ Acesso ao telefone } \\
\cline { 2 - 7 } & \multicolumn{1}{|c|}{ BR } & \multicolumn{1}{c|}{ RS } & \multicolumn{1}{c|}{ BR } & \multicolumn{1}{c}{ RS } & \multicolumn{1}{c}{ BR } & \multicolumn{1}{c}{ RS } \\
\hline 2001 & 52,68 & 88,77 & 77,63 & 89,29 & 15,17 & 40,93 \\
\hline 2002 & 55,45 & 89,74 & 80,17 & 90,73 & 19,27 & 50,83 \\
\hline 2003 & 57,8 & 92,07 & 81,92 & 92,72 & 21,82 & 59,22 \\
\hline 2004 & 57,55 & 92,43 & 81,5 & 95,23 & 25,51 & 66,28 \\
\hline 2005 & 58,86 & 93,78 & 83,47 & 95,42 & 32,25 & 76,43 \\
\hline 2006 & 61,56 & 94,65 & 86,07 & 96,43 & 37,9 & 79,58 \\
\hline 2008 & 64,11 & 95,44 & 89,07 & 98,43 & 41,91 & 76,42 \\
\hline 2009 & 66,48 & 95,61 & 91,39 & 97,73 & 50,54 & 83,64 \\
\hline 2010 & 68,44 & 95,21 & 93,33 & 98,61 & 54,45 & 88,41 \\
\hline 2012 & 70,05 & 96,22 & 94,56 & 99,22 & 60,3 & 87,82 \\
\hline 2013 & 71,66 & 97,24 & 95,79 & 99,83 & 66,16 & 87,24 \\
\hline
\end{tabular}

Fonte: Adaptado de dados do IBGE (2014).

\footnotetext{
${ }^{9}$ No Brasil e no Rio Grande do Sul vislumbram-se novas possibilidades de inserção no mercado, a exemplo do estímulo aos agricultores familiares na produção de orgânicos, via criação de mercados institucionais estimulados por políticas públicas (PAA - Programa de Aquisição de Alimentos e PNAE - Programa Nacional de Alimentação Escolar) e, também, considerando as diferentes demandas, inclusive as bioenergéticas. De acordo com o Censo do IGBE de 2006, no Estado do Rio Grande do Sul, a agricultura familiar representava $30,6 \%$ do total das áreas em hectares utilizadas pela agricultura.
} 
Uma análise da evolução do comportamento das três variáveis selecionadas de 2001-2013 permite afirmar que no Brasil e no Rio Grande do Sul a acessibilidade da população rural à água canalizada, iluminação elétrica e acesso aos serviços telefônicos aumentou sensivelmente no período. Quando analisados os dados comparativamente, pode-se verificar que se o estado gaúcho já vinha apresentando um desempenho favorável em todo o período analisado, em 2014 sua posição de liderança se torna ainda mais nítida, especialmente quando se considera a variável acesso à água canalizada. Em 2001, a iluminação elétrica foi a variável mais representativa no conjunto dos componentes da Dimensão Bem-Estar Social para o Brasil, ou seja, $77,63 \%$ da população rural possuía acesso à iluminação elétrica, sendo que no RS esse percentual foi consideravelmente maior $(89,29 \%)$.

A tabela 3 demonstra que o acesso a telefonia da população rural mostrouse como a variável de maior crescimento para o caso brasileiro e RS no interstício de 2001-2013. O país obteve o maior crescimento acumulado no acesso a telefonia, porém o RS manteve média de acessibilidade de 17,96 pontos percentuais a mais que o Brasil. Noutros termos, enquanto que no Brasil menos da metade da população rural tinha posse de telefone, no RS $3 / 4$ da população rural teve acesso a esse bem. Os resultados para o comportamento dessa variável podem ser atribuídos aos rendimentos superiores auferidos pela população rural gaúcha, em relação a rendas rurais nacionais, conforme demonstrado anteriormente (Tabela 2).

\subsection{DIMENSÃO MEIO AMBIENTE}

No âmbito do desenvolvimento, a análise das condições ambientais é crucial, uma vez que consiste na base vital da vida humana e das gerações futuras. O acirramento dos problemas inerentes a contínua destruição e exploração dos recursos naturais decorre da coexistência de dois fatores: a) exploração agrícola superior a escala sustentável, e b) vulnerabilidade gerada por instituições reguladoras fracas.

Para Gutiérrez-Espeleta (1998), os indicadores ambientais representam ferramentas para a comunicação de informações sintéticas sobre o estado do meio ambiente aos formuladores de política e ao público em geral. Além disso, permitem a provisão de bases sólidas para a tomada de decisão em todos os níveis e contribuem para uma relação sustentável entre sistema econômico e meio ambiente.

A Tabela 4 apresenta os Indicadores de Meio ambiente para o Brasil e Rio Grande do Sul que permitem comparar a participação de ambos em diferentes instituições, órgãos ambientais e práticas sustentáveis, a saber, em: i) Estrutura na área de Meio Ambiente; ii) Conselho Municipal de Meio Ambiente; iii) Fundo de Meio Ambiente; iv) Legislação específica para tratar de questões sobre Meio Ambiente; v) Comitê de Bacia Hidrográfica; vi) Comissão Interinstitucional de Educação Ambiental; e vii) Iniciativa na área de Consumo Sustentável. 
Tabela 4 - Indicadores de Meio Ambiente (\%).

\begin{tabular}{lrr}
\hline \multirow{2}{*}{ Indicadores (\%) } & \multicolumn{2}{c}{ Local } \\
\cline { 2 - 3 } & Brasil & Rio Grande do Sul \\
\hline Estrutura na área de Meio Ambiente & 90,04 & 99,40 \\
Conselho Municipal de Meio Ambiente & 67,94 & 97,18 \\
Legislação Específica para tratar de Meio Ambiente & 65,51 & 94,97 \\
Fundo de Meio Ambiente & 42,84 & 95,17 \\
Comitê de Bacia Hidrográfica & 73,14 & 75,25 \\
Iniciativa na área de Consumo Sustentável & 41,04 & 40,44 \\
Comissão Interinstitucional de Educação Ambiental & 6,39 & 1,05 \\
\hline
\end{tabular}

Fonte: Adaptado de dados do IBGE (2010).

A estrutura na área de Meio Ambiente é, em termos absolutos, o indicador que apresenta o melhor desempenho para o Brasil e o Rio Grande do Sul, com um percentual de $90,04 \%$ de posse deste serviço nos municípios brasileiros e $99,4 \%$ no caso gaúcho. Quando analisados apenas os municípios que tem secretaria exclusiva na área de meio ambiente, este percentual cai para $27,15 \%$ no caso brasileiro e $19,11 \%$ no caso gaúcho. Depreende-se, que a maior parte dos municípios que têm algum tipo de estrutura de Meio Ambiente ocorre em conjunto com outras políticas (BR 46\%; RS 61\%), subordinado a outra secretaria (BR 12\%; RS 16\%) ou a chefia do executivo (BR 4\%; RS 2\%) ou até mesmo com algum órgão de administração indireta (BR 1\%; RS 0,2\%).

É importante destacar que para a variável "Presença de Conselho Municipal de Meio Ambiente", o resultado para o Brasil foi de $(67,94 \%)$ e para o Rio Grande do Sul esse percentual é bastante superior, ou seja, $97,18 \%$ dos municípios apresentam tal entidade. Esse Conselho Municipal apresenta quatro atribuições de funcionamento nos âmbitos: a) Consultivo, b) Deliberativo, c) Normativo e, d) Fiscalizador. Tanto para o caso brasileiro como para o caso dos municípios do RS, a maior parte dos conselhos são deliberativos e consultivos (85,5\% e $80,94 \%$ para o caso brasileiro; $89 \%$ e $73 \%$ para o Rio Grande do Sul, respectivamente). Quando analisada a efetivação das reuniões dos Conselhos Municipais no ano precedente a análise, isto é, 2012, percebe-se que $75,92 \%$ dos municípios brasileiros realizaram reuniões do Conselho, enquanto que no Rio Grande do Sul este percentual foi de $83,02 \%$.

Com referência ao indicador Legislação Específica para tratar de Meio Ambiente, $65,51 \%$ dos municípios brasileiros possuem legislação específica para tratar dos assuntos ambientais. No caso gaúcho, esta porcentagem é mais elevada $(94,97 \%)$. Além disso, $19,96 \%$ dos municípios brasileiros e $8,85 \%$ dos municípios gaúchos possuem capítulo ou artigo na lei orgânica. Ainda, $13,45 \%$ dos municípios brasileiros e $20,72 \%$ dos municípios gaúchos têm Código Ambiental; $1,53 \%$ dos municípios brasileiros e 1,2\% dos municípios gaúchos possuem Lei de Unidades de Conservação. Por fim, $6,80 \%$ dos municípios brasileiros e $3,22 \%$ possuem Capítulo ou artigo no Plano Diretor.

Dos municípios que possuem Fundo de Meio Ambiente, que atua como agente financiador de planos, programas e projetos em diferentes âmbitos, tais como educação, recuperação, conservação e pesquisa ambiental, o contraste entre o caso brasileiro e o gaúcho foi significativo, uma vez que apenas $42,84 \%$ dos municípios do país contam com um Fundo de Meio Ambiente, enquanto no Rio Grande do Sul essa 
porcentagem é de $95,17 \%$. No que diz respeito ao percentual de municípios que fazem parte da Bacia Hidrográfica, o Brasil $(73,14 \%)$ e o Rio Grande do Sul $(75,25 \%)$, apresentam resultados similares.

Os municípios brasileiros possuem um percentual de $41,01 \%$ de iniciativa na área de Consumo Sustentável e os gaúchos 40,44\%, como redução do uso de sacolas plásticas (BR 16,43\%; RS 16,70\%); sustentabilidade ambiental das instituições públicas (BR 7,48\%; RS 2,82\%); redução do consumo de água ou energia (BR 19,62\%; RS 17,50\%); uso de critério ambiental em compra ou concorrência pública (BR 7,81\%; RS 5,83\%); entre outros.

Cerca de 6,39\% de municípios brasileiros participam da Comissão Interinstitucional de Educação Ambiental, 11\% alegam desconhecer as atribuições desta Comissão. Referentes aos municípios que participam desta Comissão, 77,39\% frequentam as reuniões, $7,39 \%$ alegaram não promover reuniões e os restantes $15,22 \%$ não compareceram às reuniões realizadas. No caso do Rio Grande do Sul, a porcentagem de municípios que participam da Comissão Interinstitucional de Educação Ambiental é ainda mais baixa, com 1,05\%, ou seja, apenas 7 municípios dos 497 existentes no território gaúcho, além de que 5 destes comparecem a reunião e 84 municípios alegam não conhecer a referida Comissão.

\section{6 ÍNDICE DE DESENVOLVIMENTO RURAL}

O Índice de Desenvolvimento Rural (IDR) foi construído com base nas dimensões População, Educação, Renda, Bem-Estar Social e Meio Ambiente. Para cada dimensão, foi calculado o IDR brasileiro e riograndense para o ano de 2010. Especificamente para o caso da dimensão Meio Ambiente, as informações quantitativas correspondem ao ano de 2013.

Tabela 6 - Índice de Desenvolvimento Rural (Brasil e RS).

\begin{tabular}{lrr}
\hline \multirow{2}{*}{ Dimensão } & \multicolumn{2}{c}{ Local } \\
\cline { 2 - 3 } & Brasil & Rio Grande do Sul \\
\hline População & 0,58 & 0,57 \\
Educação & 0,77 & 0,92 \\
Bem-estar Social & 0,75 & 0,94 \\
Renda & 0,08 & 0,33 \\
Meio Ambiente & 0,55 & 0,72 \\
\hline IDR & 0,546 & 0,696 \\
\hline
\end{tabular}

Fonte: Elaboração própria com base em dados do IBGE (2010).

O Índice de Desenvolvimento Rural estimado para o Rio Grande do Sul foi de 0,696 . Dentre todas as dimensões analisadas, somente dois IDR parciais tiveram resultado inferior a este percentual: a Dimensão Renda $(0,33)^{10}$ e a Dimensão População $(0,57)$. Estes resultados corroboram a perspectiva analítica estrutural do

\footnotetext{
${ }^{10}$ Há uma complexidade na análise da renda em função da base de dados do IBGE não considerar a renda de autoconsumo. Este fato, a priori, não compromete a análise comparativa, apesar de não estar totalmente isento de algumas discrepâncias pois, nada garante todas as regiões apresentam os mesmos níveis de autoconsumo.
} 
desenvolvimento rural defendida por Caio Prado Jr. (1987) e Rangel (2000), em que a pressão exercida pela estrutura concentradora da terra condiciona o êxodo no campo, reduzindo a renda da população rural.

Ressalva-se que os resultados mais críticos observados para o IDR Renda estão relacionados à elevada proporção de pessoas que não possuem rendimento no meio rural (30,73\% dos brasileiros e $11,83 \%$ dos gaúchos) (IBGE, 2010). Mesmo que a produção para autoconsumo seja expressiva, o acesso a rendimentos possibilita o atendimento a necessidades cotidianas básicas, como transporte, serviços em saúde, energia elétrica, comunicação, lazer, dentre outros.

O IDR parcial para a dimensão Meio Ambiente $(0,72)$ para este estudo permite apenas inferir sobre o marco institucional, com bom desempenho. O Rio Grande do Sul, neste caso, apresentou um resultado expressivamente melhor que a média para o país, em que se dá visibilidade ao arcabouço institucional, com a organização de Conselhos, Legislação, Fundos, Comissões, Estrutura e Comitês.

Em relação ao IDR parcial para a dimensão Educação $(0,92)$, foi a única dimensão que apresentou uma deterioração expressiva nos seus resultados em relação a 2000. Estes resultados podem ser parcialmente explicados na seção 4.1 deste trabalho, que avaliou a evolução da população rural e a densidade demográfica. Neste sentido, verificou-se que tanto no Brasil quanto no Rio Grande do Sul, ao mesmo tempo em que a população rural decrescia, contrariamente a densidade demográfica se elevava consideravelmente no período analisado.

Nesta linha de análise, a literatura especializada mostra que a redução de indivíduos no meio rural está associada ao processo de migração de jovens que buscam aperfeiçoamento nas cidades. Por outro lado, a população do meio rural, cada vez mais é composta por indivíduos de menos escolaridade e de populações idosas ${ }^{11}$. Além disso, as transformações agrícolas, o uso intensivo de tecnologia e novos processos de mecanização, assalariamento dos trabalhadores, a redução da demanda de trabalho físico/braçal, incita de forma crescente à contratação de mão de obra permanente ou temporária masculina, o que denota um aumento da segregação de gênero (MAIA, BUAINAIN, 2015).

Apesar destes resultados, Ney e Hoffmann (2009) enfatizam alguns exemplos que são consequências do baixo nível de escolaridade da população, como: i) baixa produtividade do trabalho; ii) incipiente participação na vida social e política; iii) fraca compreensão no planejamento familiar e saúde; iv) inconformidade da renda e v) acirramento da desigualdade social. Desta forma, enfatiza-se a relevância da expansão e disponibilidade do exercício do estudo, inclusive para os idosos residentes no meio rural.

Por fim, a Dimensão Bem-Estar Social com o maior valor $(0,94)$ apresentou melhoras consideráveis ao passar dos anos, com o aumento da posse de bens essenciais como telefone (meio de comunicação), iluminação elétrica e água canalizada. Salienta-se que, dentre os indicadores considerados, o de maior acesso por parte da população rural foi a iluminação elétrica, seguida de água canalizada e telefone.

\section{CONSIDERAÇÕES FINAIS}

A presente pesquisa buscou construir um índice de desenvolvimento rural

\footnotetext{
${ }^{11} \mathrm{O}$ aumento do envelhecimento da população no meio rural brasileiro não ocorre de modo diferente do que no mundo, porém, para o país tem sua explicação bastante vinculada às mudanças introduzidas pela Constituição de 1888, através da criação da aposentadoria rural e descentralização de algumas políticas públicas, como o Sistema Único de Saúde (SUS).
} 
para o Rio Grande do Sul, considerando o interstício temporal de 2010-2013. Para tanto, realizou-se uma análise multidimensional, contemplando as dimensões: população, renda, educação, bem-estar social e meio ambiente. Os indicadores avaliados para o Rio Grande do Sul mostraram melhor desempenho quando comparados aos resultados para o Brasil. Pode-se estimar o índice de desenvolvimento rural para o RS em 0,69.

Considerando-se as variáveis analisadas, a dimensão que apresentou pior resultado quando da construção do índice de desenvolvimento rural foi a renda, seguida da dimensão população. Ressalva-se a limitação dos dados sobre a dimensão ambiental, que permite apenas inferir sobre o marco institucional, com bom desempenho, o que equivale afirmar que o Rio Grande do Sul apresenta melhores perspectivas do que o Brasil frente a dada situação ambiental. Uma análise mais completa desta dimensão deveria incluir variáveis como: poluição de água, poluição do ar e uso de agroquímicos nas atividades agrícolas, o que já fora mencionado por Kageyama (2004) como o principal problema enfrentado pelo RS quando de sua análise sobre o desenvolvimento gaúcho.

Por fim, julga-se importante promover estudos mais amplos de pesquisas prospectivas capazes de revelar as implicações do crescimento dos agronegócios, cuja tecnologia poupadora de trabalho pode estar implicando paradoxalmente na renda rural. Além disso, deve-se investigar seus impactos na biodiversidade e nas demais variáveis relevantes de análise capazes de promover assimetrias no desenvolvimento rural atual e futuro. Infere-se a necessidade de implementação de políticas públicas e privadas que considerem o território como um lugar que deva ser socialmente construído e, para tal, assegurar formas participativas de ações capazes de minimizar as vulnerabilidades da população rural.

As estratégias para a melhoria da renda da população rural também vinculam-se, sobretudo, às ações assertivas das opções produtivas através de incursões locais e regionais da extensão rural. Sobretudo, a promoção de melhores níveis de vida no campo são condição essencial para o desenvolvimento regional e nacional.

Este estudo enfatizou, com base na pesquisa de Kageyama (2006), que o problema ambiental do RS é mais latente do que a média para o país. A despeito dos avanços conquistados nos últimos anos, a conjuntura atual, de crescente aumento nos níveis de usos de agrotóxicos, incita à necessidade de novos levantamentos de informações e ampliação de escopos analíticos, na direção das implicações desses processos no desenvolvimento para o país e Rio Grande do Sul.

\section{REFERÊNCIAS}

\section{ABRAMOVAY, R. Funções e medidas da ruralidade no desenvolvimento contemporâneo. Rio de Janeiro: IPEA, 2000.}

BONNAL, P. Referências e considerações para o estudo e a atuação dos programas de desenvolvimento territorial (PRONAT e PTC) na perspectiva da redução da pobreza em territórios rurais. In: MIRANDA, Carlos; TIBURCIO, Breno (Orgs.). Políticas de desenvolvimento territorial e enfrentamento da pobreza rural no brasil. Brasília: Instituto Interamericano de Cooperação para a Agricultura, 2013.

BRASIL. Cadernos de estudos desenvolvimento social em debate, n. 23. Brasília, DF: Ministério do Desenvolvimento Social e Combate à Fome; Secretaria de Avaliação e Gestão da Informação, 2015. 
BRASIL. Ministério da Educação e Cultura. Educação do Campo. Marcos normativos. Brasília, SECADI, 2012.

BRASIL. Ministério da Educação e Cultura. Subsídios para o planejamento da educação no meio rural. Brasília, MEC, DDD, 1979.

CHALITA, M. A. N. Desenvolvimento rural, agricultura e natureza: novas questões de pesquisa. Agricultura em São Paulo, v. 52, n.1, p. 97-113, jan/jun, 2005.

CONTERATO, M. A. Dinâmicas regionais do desenvolvimento rural e estilos de agricultura familiar: uma análise a partir do Rio Grande do Sul. 2008. 290f. Tese de Doutorado (Programa de Pós-Graduação em Desenvolvimento Rural) Universidade Federal do Rio Grande do Sul.

CONTERATO, M. A.; SCHNEIDER, S.; WAQUIL, P. D. Desenvolvimento rural no Estado do Rio Grande do Sul: uma análise multidimensional de suas desigualdades regionais. Redes, v. 12, n. 2, p. 163-195, 2008.

DATASUS. Departamento de informática do SUS. Descrição das variáveis disponíveis para tabulação. Acessado em 20/06/2017. Disponível em: http://tabnet.datasus.gov.br/cgi/ibge/alfdescr.htm.

DELGADO, G. C. Capital financeiro e agricultura no Brasil, 1965-1985. São Paulo Editora, 1985.

FEIX, R. D.; LEUSIN JÚNIOR, S.; AGRANONIK; C. Painel do agronegócio no Rio Grande do Sul, 2017. Porto Alegre: FEE, 2017.

FREITAS, T. et al. Desenvolvimento humano e bem-estar no meio rural como superação da vulnerabilidade: o caso de Arroio do Tigre/RS. Colóquio - revista do desenvolvimento regional, v. 11, n. 2, jul/dez, 2014.

GRAZIANO DA SILVA, J. Quem precisa de uma estratégia de desenvolvimento. In: José Graziano da Silva, Jean Marc e Bianchini debatem O Brasil Rural precisa de uma estratégia de desenvolvimento. Brasília: MDA/CNDRS/NEAD, 2001.

GUTIERREZ-ESPELETA, E. E. Designing environmental indicators for decision makers. Disponível em: http://isi.cbs.nl/iamamember/CD5Mexico1998/inviter/DIN7SP2.HTM. Acesso em: 20 Jul. 2017.

IBGE. Instituto Brasileiro de Geografia e Estatística. Censo Demográfico. Disponível em: http://www.ibge.gov.br. Acesso em: 02 Mar. 2017.

IBGE. Instituto Brasileiro de Geografia e Estatística. Tendências Demográficas. Disponível em: http://www.ibge.gov.br. https://biblioteca.ibge.gov.br/visualizacao/livros/liv34956.pdf. Acesso em: 12 Jan. 2019.

KAGEYAMA, Â. Desenvolvimento rural no Rio Grande do Sul. A Diversidade da Agricultura Familiar. Porto Alegre: Editora da UFRGS, 2006.

KAGEYAMA, Â. Desenvolvimento Rural: conceito e medida. Cadernos de Ciência \& 
Tecnologia, v. 21, n. 3, p. 379-408, set./dez. 2004.

KAGEYAMA, Â. Desenvolvimento Rural: conceitos e aplicações ao caso brasileiro. Porto Alegre: Editora da UFRGS, 2008.

MAIA, A. G.; BUAINAIN, A. M. O novo mapa da população rural brasileira. Confins (Paris), v. 2015, n. 25, p.1-26, 2015.

NEY, M. G.; HOFFMANN, R. Educação, concentração fundiária e desigualdade de rendimentos no meio rural brasileiro. Revista de economia e sociologia rural, v. 47 , n. 1, p. 147-181, 2009

OLIVEIRA, G. B. Uma discussão sobre o conceito de desenvolvimento. Revista da FAE, Curitiba, v. 5, n. 2, p. 41-48, mai./ago, 2002.

PLOEG, J. D. V. D.; RENTING, H.; BRUNORI, G.; KNICKEL, K.; MANNION, J.; MARSDEN, T.; ROEST, K.; SEVILLA-GUZMÁN, E.; VENTURA, F. Rural development: From practices and policies towards theory, Sociologia Ruralis, v. 40, n. 4, p. 497$511,2000$.

PRADO JÚNIOR, C. A revolução brasileira. São Paulo: Brasiliense, 1987.

RANGEL, I. A questão agrária brasileira. In: Q Questão agrária, industrialização e crise urbana no Brasil. Porto Alegre: Ed. da UFRGS, 2000.

SCHNEIDER, S. A abordagem territorial do desenvolvimento e suas articulações externas. In: I FÓRUM INTERNACIONAL TERRITÓRIO, DESENVOLVIMENTO RURAL E DEMOCRACIA, 2003, Fortaleza. Anais...Fortaleza: 2003.

SCHNEIDER, S. A abordagem territorial do desenvolvimento rural e suas articulações externas. Sociologias, Porto Alegre, v. 6, n. 11, p. 88-125, 2004.

SCHNEIDER, S. Situando o desenvolvimento rural no Brasil: o contexto e as questões em debate. Revista de Economia Política, v. 30, n. 3, p. 511-531, 2010.

SEN, A. Desenvolvimento como liberdade. São Paulo: Editora Schwarcz, 2010.

SETH, S; VILLAR, A. Human development, inequality, and poverty: Empirical findings. OPHI Working Paper 111, University of Oxford, 2017.

SOUZA, N. J. Desenvolvimento econômico. São Paulo: Atlas, 2012.

STEGE, A. L.; PARRÉ, J. L. Fatores que determinam o desenvolvimento rural nas microrregiões do Brasil. Revista Franco-Brasilera de Geografia, n. 19, 2013.

SUNKEL, O.; PAZ, P. El subdesarrollo latinoamericano y la teoría del desarrollo. México: Siglo XX Editores, 1988.

WAQUIL, P. D.; GIANLUPPI, L. D. F.; MATTOS, E. J. As múltiplas dimensões do desenvolvimento rural no Rio Grande do Sul. Ensaios FEE, Porto Alegre, v. 26, Número Especial, p. 117-142, 2005. 